\title{
A mulher em São Paulo colonial
}

\author{
Carlos de Almeida Prado Bacellar *
}

O objetivo desta nossa pequena reflexão é trazer algumas constribuiçōes para a discussão acerca do papel da mulher em nossa sociedade colonial. Nesta análise, buscamos fugir da realidade dos grandes núcleos urbanos, já por nós conhecida ${ }^{1}$, escolhendo como alvo duas vilas do interior ca Capitania de São Paulo: Sorocaba e Itu. Apesar de constituírem núcleos econômicos de grande importância no contexto regional, não possuíam uma atividade nitidamente urbana. Pelo contrário, seu dia-a-dia era basicamente rural, seja voltado para a produção de açúcar (Itu), seja para a comercialização de animais (Sorocaba).

Como fonte documental, utilizamos duas séries distintas. Para as duas vilas em questão pudemos consultar as listas nominativas anuais de habitantes feitas no ano de $1818^{2}$. Para a vila de Sorocaba, dispomos, ainda, da coleção dos Autos Civeis do periodo $1720-1820^{3}$, composta por todos os processos litigiosos, com exceção dos crimes.

Muito se tem dito acerca do papel da mulher em nossa sociedade colonial. Há até bem pouco tempo, a imagem corrente era de que o sexo feminino sempre esteve submisso aos poderes ditos "patriarcais" do sexo oposto. Nesse sentido, os trabalhos de Gilberto Freyre em muito contribuíram, caracterizando esposas e filhas como sempre cercadas pelo poder do marido ou pai ${ }^{4}$.

- Departamento de Historia. CEDHAL, Universidad de São Paulo (USP, Brasil).

' Vide, por exemplo, Dias, Maria Odila Leite da Silva, Quotidiano e Poder em São Paulo no século XIX. São Paulo, Brasiliense, 1984.

2 As listas nominativas, abrangendo todas as vilas paulistas dos periodo 1765-1836, são fontes extremamente ricas em informações, individualizadas por domicilio e por habitante: nome, idade, cor, situaçăo familiar, sexo, naturalidade e ocupação, indicadas para cada pessoa livre, agregada ou escrava presente em cada domicílio. Esta coleçāo encontrase arquivada no Arquivo Público do Estado de São Paulo.

${ }^{3}$ Documentação esta também encontrada no Arquivo Público do Estado de São Paulo.

${ }^{4}$ FreYre, Gilberto, Casa Grande e Senzala, 11. ${ }^{a}$ ed. Rio de Janeiro, José Olympio, 1964. 
No actual estado das discussões, resta difícil sustentar algumas dessas posiçōes. Sabemos, graças aos mais diversos autores, que a mulher tinha papel puito mais efetivo e marcante do qué, até então, se supunha ${ }^{5}$.

Ao analisar as listas nominativas pretendemos melhor caracterizar a situação femenina nas vilas do Oeste Paulista situadas próximas à frente pioneira de colonização ${ }^{6}$, buscando identificar as opçōes de sobrevivéncia das mulheres solitárias, fossem elas viúvas, casadas (com o marido ausente) ou solteiras.

As duas vilas caracterizavam-se, fundamentalmente, pela sua pequena dimensão. Longe de constituirem um núcleo urbano significativo, eram ralas e pouco frequentadas, estando quase toda sua população dispersa pelas fazendas, sítios e roças. Como os municípios abrangiam uma extensão territorial considerável, era normal que estas propriedades rurais se localizassem afastadas da vila, tornando o conto mais difíciles e menos assiduo.

Saint-Hilaire descreveu essas vilas como locais êrmos, onde a população quase sempre estava ausente, frequentadas quase apenas aos fins-de-semana: “Nos domingos e dias-santos Itu se enche de animação. Nesses dias, como já disse, os fazendeiros das redondezas vão à cidade assitir à missa, mas durante a semana as principais casas ficam fechadas, e as ruas desertas" ?.

Através das listas nomativas, para o ano de 1818, podemos verificar como as ocupaçōes de seus habitantes mesmo numa localidade pequena, eram variadas. Simultaneamente, identificamos que, para as mulheres, a maior parte dessas actividades não era acessivel. No total, são enumeradas, pelas listas, aproximadamente 50 ocupações. Destas, apenas 15 são representadas por mulheres:

Algumas atividades manuais eram tipicamente masculinas, tais como ferreiro, algaiate, sapateiro, carpinteiro e feitor, Outras, como costureira, fiandeira, rendeira e louceira eram exclusividade femininas. A maioria das

${ }^{5}$ Vide, Silva, op. cit.; PrIORe, MARY del, A Mulher na História do Brasil. São Paulo, Contexto, 1988; Motr, Maria Lucia de Barros, Submissão e Resistência - A Mulher na Luta contra a Excravidão. São Paulo, Contexto, 1988.

${ }^{6}$ No período em questão, reiniciava-se o amplo movimento de expansão demográfica e econômica em direção ao Oeste, em toda a Capitania de São Paulo. Com o fortalecimiento da economia regional, graças à implantação de uma punjante rede de engenhos de açúcar, Itu e Sorocaba transformaram-se em de ocupação territorial.

7 Saint-HILAIRE, Auguste de, Viagem à Província de São Paulo. Belo Horizonte, Ed. Itatiaia; São Paulo, Edusp, 1976, pág. 174. 
Tabela 1. Ocupação das Mulheres Chefes de Domicilio (Itu e Sorocaba, 1818)

\begin{tabular}{|c|c|c|}
\hline \multirow{2}{*}{ Ocupação } & \multicolumn{2}{|c|}{ Número de mulheres } \\
\hline & itu & Sorocaba \\
\hline Fiandeira & 84 & 179 \\
\hline Costureira $\ldots \ldots \ldots \ldots \ldots \ldots \ldots$ & 72 & 45 \\
\hline Lavradora $\ldots \ldots \ldots \ldots \ldots \ldots \ldots \ldots$ & 70 & 105 \\
\hline Vive dos jornais dos escravos ... & 29 & 3 \\
\hline Vive de esmolas .............. & 28 & 23 \\
\hline Senhora de engenho $\ldots \ldots \ldots \ldots \ldots \ldots \ldots \ldots$ & 22 & 5 \\
\hline Vive den seu negócio $\ldots \ldots \ldots \ldots \ldots$ & 13 & 4 \\
\hline Vive de seu trabalho & 9 & 2 \\
\hline Louceira ............... & 7 & 7 \\
\hline Tecelãa $\ldots \ldots \ldots \ldots \ldots \ldots \ldots \ldots \ldots \ldots \ldots \ldots \ldots \ldots \ldots \ldots \ldots \ldots$ & 7 & 4 \\
\hline Vive de suas Agências $\ldots \ldots \ldots \ldots \ldots \ldots \ldots \ldots$ & 6 & 2 \\
\hline Rendeira $\ldots \ldots \ldots \ldots \ldots$ & 6 & 16 \\
\hline 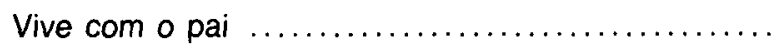 & 3 & - \\
\hline Planta čano no engenho de pai $\ldots \ldots \ldots \ldots \ldots \ldots$ & 1 & 1 \\
\hline Vive dos jornais de seu filho $\ldots \ldots \ldots \ldots \ldots \ldots \ldots$ & 1 & 1 \\
\hline Taberneira $\ldots \ldots \ldots \ldots \ldots \ldots \ldots \ldots \ldots \ldots \ldots \ldots \ldots \ldots \ldots \ldots$ & - & 8 \\
\hline Vendeira $\ldots \ldots \ldots \ldots \ldots \ldots \ldots \ldots \ldots \ldots \ldots \ldots \ldots$ & - & 2 \\
\hline 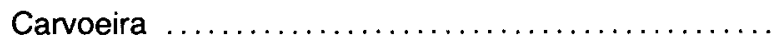 & - & 1 \\
\hline Não indicada & 3 & 27 \\
\hline Total & 362 & 435 \\
\hline
\end{tabular}

ocupações, contudo, tendia a ser exercida indiferentemente por homens ou mulheres. O que importava, então, eram outras variáveis: ideade, cor, estado civil e status social, para definir quais mulheres podiam exercem cada ocupação. É o que veremos a seguir.

\section{A MULHER QUE ERA «DONA»}

Em nossa Dissertação de Mestrado, haviamos discutido como que uma elite agrária, surgida em São Paulo somente a partir de meados do século XVIII, buscou criar "sinais" diferenciadores de seu novo status so- 
cial, relacionando-os à nova e recém-implantada lavoura caravieira, monocultora e escravista, de exportação ${ }^{6}$. A adoção de patentes e títulos nobiliárquicos, a organização de genealogias, 0 início da práctica de transmissão do nome de família para os descendentes, e a preocupação em dar nomes próprios às propriedades rurais, há pouco transformadas em engenhos de açúcar e juridicamente regularizadas, tudo são sinais inequivocos de uma nova realidade social.

Entre as mulheres, ou, mais precisamente, entre as esposas desses grandes proprietários, difunde-se a adoção do tratamento "Dona" enquanto diferenciador social. Este tratamento, todavia, era reservado apenas, a tão somente, às esposas ou viúvas desses proprietários, ou, então, às filhas que ainda residiam, solteiras, junto aos pais. Não encontramos casos de mulheres solteiras, chefiando um domicilio, recebendo tal tratamento. Assim, o status de "Dona" seria inerente à mulher regularmente casada, de acordo com todas as normas sociais.

$\mathrm{Na}$ vila de ltu descobrimos 35 mulheres chefes-de domicílio que eram tratadas como «Donas". Possuiam, em média, 15 escravos, índice muito acima dos 7,2 escravos possuídos em média, pelas mulheres proprietárias de escravos, ou dos 2,0, em média, para todos os domicilios chefiados, ou dos 2,0 em média, para todos os domicilios chefiados por mulheres. Dessas 25 mulheres, havia 1,9 senhoras de engenho, 9 que viviam dos jornais de seus escravos, 6 lavradoras e, curiosamente, uma fiandeira. Todas possuíam, en média, mais escravos do que o total de mulheres a exercerem a mesma actividade. Assim, as lavradoras com título possuíam, em média, 8 escravos, contra uma média de um escravo para o conjunto de todas as lavradoras.

Em Sorocoba havia somente 11 “Donas» sendo 5 senhoras de engenho, duas negociantes com loja e 4 agricultoras. A média de escravos que possuíam é de 18 , superior à de Itu, e também superior à media apresentada pelas proprietárias em geral da mesma vila $(5,1)$ e por todos os domicílios chefiados por mulheres $(1,0)$. Sorocaba diferencia-se, portanto, de Itu, por uma maior concentração de escravos nas mãos de poucas mulheres. As «Donas" de Sorocaba possuiam mais escrabos do que suas congêneres de itu, enquanto o restante das proprietárias de escravos os possuiam em índices menores que as ituanas.

\footnotetext{
${ }^{8}$ Bacellar, Carlos A. P., Os Senhores da Terra - Familia e Sistema Sucessório entre os Senhores de Engenho do Oeste Paulista, 1765 - 1855. São Paulo, Dissertaçāo de Mestrado pela FFLCH-USP, 1987.
} 
Internamente ao grupo de mulheres portadoras de título, percebemos uma hierarquia de riqueza, indicada pela posse de escravos. Em Itu, a maior média de cativos diz respeito às senhoras de engenho, com 21 escravos; vêm, a seguir, as lavradoras (média de 8 escravos), e as que vivem dos jornais de seus escravos (média de 6 escravos). A maior riqueza das senhoras de engenho vem reafirmar que a produção de açúcar era, por excelência, o melhor meio de se enriquecer em São Paulo colonial ${ }^{9}$.

Estas "Donas", todas viúvas, compunham um segmento enriquecido da sociedade, mas restrito em dimensão. Em Itu, eram 9,5\% mulheres chefes-de-domicilio, mas possuiam 527 dos 726 escravos do grupo, ou seja, $72,6 \%$ do total. Em Sorocaba, eram apenas $2,5 \%$ das mulheres chefes, mas possuiam 197 dos 452 escravos do grupo, isto é, $43,6 \%$ do total. O menor índice relativo a Sorocaba é consequência do menor número de «Donas" dessa vila. A concentração de escravos, contudo, se reafirma, caso se analise a representatividade dos domícilios chefiados por mulheres e possuidores de escravos no contexto de cada vila. Assim, os docimicílios com escravos representam $27,9 \%$ dos domicilios chefiados por mulheres em Itu, e $20,5 \%$ em Sorocaba. Comprova-se, pois, a maior difusão de mão-de-obra escrava nos fogos ituanos.

\section{A BRANCA, A PARDA E A NEGRA}

Todas as mulheres apelidadas "Donas" eram da cor branca. Mas, na realidade, esta cor não era apanágio das mulheres de posse, pois haviam brancas que eram extremamente pauperizadas.

Em Itu, eram 18 as brancas que pediam esmolas, contra 7 pardas e 3 pretas. En Sorocaba, as mendicantes eram 17 brancas e 6 pardas. Aliás, as brancas eram em número superior na maior parte das ocupações, independente das posses, o que nos leva a deduzir que essas mulheres tinham maior facilidade para se estabeceren autônomas, como chefes de domicílio.

Embora toda mulher solitária com posses quase sempre fosse branca, ser branca não livrava uma mulher de exercer as piores ocupa-

${ }^{9}$ A respeito do enriquecimento diferenciado, frente ao todo da sociedade, dos proprietários de engenhos de açúcar do Oeste paulista, vide Barcellar, op. cit. 
Tabela 2. Distribuição segundo a cor (Itu, 1818)

\begin{tabular}{|c|c|c|c|c|}
\hline \multirow{2}{*}{ Ocupaçāo } & \multirow{2}{*}{$\begin{array}{l}\text { N. }{ }^{\circ} \\
\text { Fogos }\end{array}$} & \multicolumn{3}{|c|}{ Cor } \\
\hline & & B & $\mathrm{Pa}$ & PP \\
\hline Fianderira & 84 & 55 & 23 & 6 \\
\hline Costureira & 72 & 42 & 21 & 9 \\
\hline Lavradora & 70 & 50 & 19 & 1 \\
\hline Vive dos jornais dos escravos & 29 & 28 & 1 & - \\
\hline Vive de esmolas $\ldots \ldots \ldots \ldots$ & 28 & 18 & 7 & 3 \\
\hline Senhora de engenho $\ldots \ldots \ldots$ & 22 & 22 & - & - \\
\hline Vive de seu negócio & 13 & 6 & 6 & 1 \\
\hline Vive de seu trabalho & 9 & 6 & 2 & 1 \\
\hline Louceira .......... & 7 & 1 & 5 & 1 \\
\hline Tecelã .. & 7 & 4 & 3 & - \\
\hline Vive de suas Agências & 6 & 3 & 3 & - \\
\hline Rendeira $\ldots . . . \ldots \ldots$ & 6 & 5 & 1 & - \\
\hline Vive com o pai & 3 & 3 & - & - \\
\hline Planta cana no engenho do pai & 1 & 1 & - & - \\
\hline Vive dos jornais de seu filho & 1 & - & 1 & - \\
\hline Taberneira & 1 & - & - & 1 \\
\hline Não indicada & 3 & 3 & - & - \\
\hline Total & 362 & 247 & 92 & 23 \\
\hline
\end{tabular}

ções. Sozinha, chefiando seu domicilio, tinha que lutar para sobreviver e sustentar seus dependentes.

\section{O ESTADO CIVIL}

O estado civil das mulheres chefiando domicilio eram diferenciado de acordo com a cor. Viúvas, casadas solitárias e solteiras distribuíam-se desigualmente, conforme mostra a Tabela 3.

As Tabelas 3 e 4 demonstram uma particularização das realidades de Itu e Sorocaba. A primeira, e mais notável, diferença entre as duas vilas diz respeito à presença de mulheres casadas e solitárias. Em Sorocaba, tais mulheres aparecem em número proporcionalmente mais elevado, como reflexo da economia de comercialização do muar. Tropeiros, seus maridos ausentavam-se por largos espaços de tempo, numa prática 
Tabela 3. Distribuição das mulheres segundo o estado civil

\begin{tabular}{|r|c|l|l|c|}
\hline \multirow{2}{*}{ Cor } & \multicolumn{4}{|c|}{ Estado civil } \\
\cline { 2 - 5 } & Viúvas & Solteiras & Casadas & Total $(\%)$ \\
\hline $\mathrm{B} \ldots \ldots \ldots \ldots \ldots$ & 137 & 72 & 38 & $247(68,2)$ \\
$\mathrm{Pa} \ldots \ldots \ldots \ldots \ldots$ & 37 & 47 & 8 & $92(25,4)$ \\
$\mathrm{PP}$ & $4 \ldots \ldots \ldots \ldots$ & 18 & 1 & $23(6,4)$ \\
\hline \multicolumn{1}{|c|}{ Total \% $\ldots$} & $178(49,2)$ & $137(37,8)$ & $47(13,0)$ & $362(100,0)$ \\
\hline
\end{tabular}

Tabela 4. Distribuição das mulheres segundo o estado civil

\begin{tabular}{|r|c|c|l|c|}
\hline \multirow{2}{*}{ Cor } & \multicolumn{4}{|c|}{ Estado civil } \\
\cline { 2 - 5 } & Viúvas & Solteiras & Casadas & Total $(\%)$ \\
\hline B $\ldots \ldots \ldots \ldots$. & 190 & 79 & 74 & $343(78,9)$ \\
Pa $\ldots \ldots \ldots \ldots$. & 41 & 28 & 17 & $86(19,8)$ \\
PP $\ldots \ldots \ldots \ldots$. & 3 & 3 & - & $6(1,3)$ \\
\hline Total \% .. & $234(53,8)$ & $110(25,3)$ & $91(20,9)$ & $435(100,0)$ \\
\hline
\end{tabular}

bem menos usual do que ocorria em Itu. As listas nominativas fornecem exemplos significativos dessas ausências de marido:

- Gertrudes Maria Nogueira: seu marido, Francisco Cubas, está "auzente $p .{ }^{2}$ o Sul a 14 anos" ${ }^{10}$;

- Joana Maria: seu marido, Joaquim Caetano, está "auzente p. ${ }^{a}$ Cuyaba a 9 anos" "';

- Caetana Maria: seu marido, Manuel Roiz da Mota, está «auzente p. ${ }^{\text {a }}$ o Sul a 8 anos" ${ }^{12}$.

Outra diferença perceptível é a quase ausẽncia de negras chefiando domicilios em Sorocaba $(1,4 \%)$, contra uma presença mais marcante em Itu $(6,4 \%)$. De modo semelhante, os fogos chefiados por pardas é mais comun em Itu $(25,4 \%)$ do que em Sorocaba $(19,8)$. Podemos aventar a hipótese de que tal realidade derive da presença mais maciça da mão-

\footnotetext{
${ }^{10}$ Lista nominativa de Sorocaba, $1801,1 .^{a} \mathrm{Cia}$, fogo 261.

11 ídem, 1801, 1. Cía., fogo 291.

12 Ídem, 1801, 1. Cia., fogo 371.
} 
de-obra escrava na economia ituana, fortemente monocultora, em relaçāo à sorocabana, mais marcada pelo tráfico do muar e, portanto, menos carente de cativos.

As Tabelas 3 e 4 indicam também que, em ltu, havia uma predominãncia de mulheres brancas viúvas, contra um maior número de pardas e pretas solteiras. Já em Sorocaba, brancas e pardas são predominantemente viúvas, restando pouco significativa a repartição das pretas. Tais constatações são de difícil análisis. Os dados de Itu parecem indicar uma situação de vida mais dificil para as duas últimas categorias, pardas e pretas. Enquanto somente $29 \%$ das mulheres brancas são solteiras, esse indice sobe para $51 \%$ para as pardas e $78 \%$ para as pretas. Aparentemente, pardas e, principalmente, pretas, tinham maior dificuldade para contrair matrimônio. No caso de Sorocaba, o número mais elevado de pardas viuvas talvez seja fruto do contínuo viajar dos maridos, sujeitos a uma mortalidade mais elevada.

O estado de celibatária não era, em absoluto, indicação de que estas mulheres não tinham uma vida sexual. Dentre as solteiras, várias tinham filhos: para Itu, $26 \%$ das brancas, $44 \%$ das pretas e $55 \%$ das pardas; para Sorocaba, $39 \%$ das brancas e $71 \%$ das pardas. Semelhante situação viria a confirmar que pretas e pardas efetivamente não casavam por falta de condições econômicas e de oportunidade, mas mantinham laços mais ou menos estáveis com seus companheiros. Já as brancas tendiam, de acordo com os dados, a não se transformarem em mães solteiras, permanecendo efetivamente celibatárias ${ }^{13}$.

O celibato definitivo, conjugado à ausência de filhos, era, em Itu, mais representativo para as mulheres brancas (32\%), seguidas pelas pardas $(15 \%)$ e pretas $(11 \%)$. Em Sorocaba, haviam 19 celibatárias definitivas de cor branca $(24,1)$ e uma preta. São indicaçōes no sentido de que havia maiores dificultades para as brancas em arranjarem um marido, ou mesmo um companheiro, um concubino. O mesmo já não se dava com pretas e pardas, mais comumente identificadas enquanto mães solteiras.

${ }^{13}$ Esta tendência se confirma pela média de filhos presentes junto à mãe solteira. Em Sorocaba, há 1,4 filhos para cada mãe branca, contra 2,1 para pardas. Em Itu, embora con diferenças menores, as brancas têm uma média de 1,6 filhos, contra 1,8 das pardas e 1,3 das negras. 


\section{O GRUPO DOMÉSTICO}

As mulheres que chefiavam domicilios estavam quase sempre próximas ao núcleo urbano da vila. Dos 362 domicílios levantados em Itu, $60 \%$ estavam localizados nas três companhias de ordenanças de Itu que eram marcantemente urbanas: $1 .^{a}, 2 .^{a}$ e $6 .^{a}$. Em Sorocaba, $42 \%$ dos fogos levantados pertenciam à $1 .^{\text {a }}$ Companhia, correspondendente à vila.

Podemos considerar que havia dois grupos distintos de domícilio chefiados por mulheres. Um, majoritário, voltado prioritariamente para o núcleo urbano. É o caso, por exemplo, das 29 mulheres que declararam "viver dos jornais de seus escravos": 21 residiam na $1 .{ }^{a}$ Companhia, 2 na $2 .^{a}$ e 6 na $6 .^{a}$. Era, pois, uma atividade eminentemente urbana, com os cativos sendo utilizados seja como mão-de-obra alugada, seja como vendedores dos mais diversos gêneros, comestiveis ou não. Geralmente, as mulheres residentes na vila não eram citadas, a nivel de lista nominativa, como possuídoras de terras ou como usuais produtoras dos gêneros da terra.

Em oposição, as mulheres exclusivamente dedicadas à atividade agrícola (lavradoras e senhoras de engenho) quase não eram significativas nas três referidas companhias urbanas. Eram sempre proprietárias de terras, nas quais residiam, e surgiam recenseadas em companhias instaladas em áreas rurais.

A presença majoritária de mulheres chefiando domicílios no meio urbano se explica pela procura de melhores opções de sobrevivência. $\mathrm{Na}$ vila, era possivel viver de "bicos", pequenos serviços prestados aqui e acolá, da venda de quitudes ou da produção de objetos artesanais cestos, balaios, peneiras e toda uma série de pequenos objetos de uso doméstico-.

Podemos tentar caracterizar um pouco melhor esses domicílios, analisando sua composição no tocante a escravos e agregados.

A posse de escravos era fator efetivamente diferenciador de riqueza. Grande parte da população não tinha acceso à sua posse, devido aos preços elevados do elemento cativo. Ao observarmos a posse de escravos segundo a cor da proprietária, vemos que, em Itu, 99,3\% deles estavam nas mãos de mulheres brancas, como seria de se esperar. Mas, das 247 mulheres brancas, apenas 98 possuiam tais escravos, com uma média de 7,4 por domicílio. 
Tabela 5. O estado civil e a posse de escravos (Itu, 1818)

\begin{tabular}{|c|c|c|c|}
\hline Estado civil & N. ${ }^{\circ}$ escravos & $N \cdot{ }^{\circ}$ fogos & $\begin{array}{c}\text { Média } \\
\text { de escravos }\end{array}$ \\
\hline Viúva a. & 611 & 178 & 3,4 \\
\hline Viúva b. .. & 190 & 159 & 1,2 \\
\hline Viúva $\mathrm{c} . \ldots \ldots \ldots \ldots \ldots$ & 124 & 146 & 0,8 \\
\hline Solteira ............ & 63 & 137 & 0,5 \\
\hline Casada & 52 & 47 & 1,1 \\
\hline
\end{tabular}

a. Viúvas, total.

b. Viúvas, excentuando senhoras de engenho.

c. Viúvas, excentuando as «Donas".

Já o estado civil das mulheres, visto em confronto com a posse de escravos, indica que as viúvas são, em média, as maiores proprietárias. Mas tal resultado pareceu-nos forçado, devido aos desvios "para mais" provocados pela presença de poucas viúvas que, devido à dimensão excessiva e excepcional de seus plantéis, provocavam un desvio na interpretação dos dados. Assim, optamos por analisar as viúvas, tambén excluindo as senhoras de engenho (b) ou as "Donas". O resultado foi, conforme esperávamos, surpreendente. $O$ peso dessas duas categorias de mulheres mostra-se efetivo, comprovando seu caráter de elite no seio do universo observado.

Retirando-se o peso das senhoras de engenho ou "Donas", a categoria "viúvas" tem seu índice de posse de escravos rebaixado a patamares mais discretos, coincidentes para ambas as vilas. A diferenciação, então, fica por conta das mulheres casadas, com o maior índice em Itu e o menor em Sorocaba. Podemos supor que esta diferença esteja relacionada ao tipo de atividade econômica dissemelhantes das duas vilas, a primeira mais fortemente ligada à indústria açucareira, a segunda ao comércio do muar.

Quanto aos agregados, podemos perceber a ocorrência de padrões semelhantes entre as duas vilas. Pelas Tabelas 6 e 7 , verificamos que a média de agregados por fogo cresce de acordo com a faixa etária da chefe. Isto significaria que, enquanto tendência, o agregado era incorporado ao domicilio à medida em que a chefe envelhecia e mais necessitava de auxilio nas fainas cotidianas.

A presença de agregados tem relações tênues com a cor da chefe; tanto em Itu, quanto em Sorocaba, as brancas possuem 0,5 agregados, 
Tabela 6. O estado civil e a posse de escravos (Sorocaba, 1818)

\begin{tabular}{|c|c|c|c|}
\hline Estado civil & N. ${ }^{\circ}$ escravos & $N \cdot{ }^{\circ}$ fogos & $\begin{array}{c}\text { Média } \\
\text { de escravos }\end{array}$ \\
\hline Viúva a. & 369 & 234 & 1,6 \\
\hline Viúva b. & 248 & 230 & 1,1 \\
\hline Viúva c. & 172 & 223 & 0,8 \\
\hline Solteira $\ldots \ldots \ldots \ldots \ldots \ldots$ & 55 & 110 & 0,5 \\
\hline Casada $\ldots \ldots \ldots \ldots \ldots \ldots$ & 28 & 91 & 0,3 \\
\hline
\end{tabular}

a. Viúvas, total.

b. Viúvas, excentuando senhoras de engenho.

c. Viúvas, excentuando as "Donas".

Tabela 7. Média de agregados por faixa etária da mulher chefe de domicilio (Itu e Sorocaba, 1818).

\begin{tabular}{|c|c|c|c|c|c|c|}
\hline \multirow{2}{*}{ Faixa etária } & \multicolumn{3}{|c|}{ ITU } & \multicolumn{3}{c|}{ SOROCABA } \\
\cline { 2 - 7 } & Fogos & Agreg. & Média & Fogos & Agreg. & Média \\
\hline \multirow{2}{*}{10 a $20 \ldots \ldots \ldots \ldots$} & 14 & 4 & 0,3 & 11 & 2 & 0,2 \\
21 a $30 \ldots \ldots \ldots \ldots$ & 64 & 23 & 0,4 & 70 & 22 & 0,3 \\
31 a $40 \ldots \ldots \ldots \ldots$ & 68 & 24 & 0,4 & 94 & 32 & 0,3 \\
41 a $50 \ldots \ldots \ldots \ldots$ & 75 & 26 & 0,3 & 110 & 36 & 0,3 \\
51 a $60 \ldots \ldots \ldots \ldots$ & 75 & 45 & 0,6 & 80 & 56 & 0,7 \\
61 a $70 \ldots \ldots \ldots \ldots$ & 45 & 36 & 0,8 & 40 & 35 & 0,9 \\
71 e $+\ldots \ldots \ldots \ldots$ & 21 & 17 & 0,8 & 29 & 21 & 0,7 \\
\hline
\end{tabular}

em média, contra 0,4 das pardas, estabelecendo diferenças pequenas para serem melhor apreciadas.

O estado civil da chefe de fogo também se relaciona com a presença de agregados. Verificamos uma tendência, em ambas as vilas, a um predomínio de agregados entre os domícilios chefiados por solteiras (em média, 0,7 indivíduos para Sorocaba e 0,6 em Itu), seguidos, de perto, pelos domicilios chefiados por mulheres viúvas $(0,5$ individuos nas duas vilas) e por casadas $(0,3 \mathrm{em}$ Sorocaba, $0,2 \mathrm{em}$ Itu). Estes dados testemunham o maior peso, entre os domicílios chefiados por solteiras, da prática de coabitaçao entre um ou mais irmãos, ainda solteiros, dessa chefe.

Por último, podemos discutir a presença de agregados de acordo com a ocupação da chefe. Entre as ocupaçōes passiveis de análise em 
Itu ${ }^{14}$, há predominãncia de agregados entre as senhoras de engenho $(0,7$ indivíduos, em média), as mulheres que vivem dos jornais de seus escravos $(0,5)$, as lavradoras $(0,5)$ e as costureiras $(0,5)$. Em Sorocaba, ressaltam-se as rendeiras $(0,9)$, as lavradoras $(0,6)$ e as costureiras $(0,5)$, com a curiosa ausência de agregados entre as senhoras de engenho sorocabanas. Estes resultados também restam dificeis de analisar, devido à precariedade das informações a respeito da qualidade desses agregados.

Uma observação mais detalhada da real situação dos agregados nos fogos, centrada no vínculo entre a chefe e cada agregado, seria de grande importância. A identificação de possíveis laços de consanguinidade, a função doméstica, seu papel na divisão de trabalho, trariam subsídios fundamentais a um melhor explicitação do problema.

\section{AS ESTRATÉGIAS DE SOBREVIVENCIA}

A utilização, das listas nominativas enquanto fonte para o estudo da mulher em nossa sociedade colonial apresenta suas restrições. Apesar da amplitude permitida pela análise da composição dos domicílios, restanos uma descrição fria, distante do dia-a-dia sacrificado dessas mulheres.

Buscamos, assim, complementar essa visão distante com a coleção dos Autos Civeis de Sorocaba, já amplamente levantado para nosso projeto de Tese de Doutoramento. Esta documentaçāo, cobrindo basicamente o periodo 1720-1820, é extremamente rica para recuperarnos aspectos da luta cotidiana das mulheres, registrados nos diversos autos em que tomavam parte, seja como vítimas, seja como autoras, seja como simples figurante.

A luta pela sobrevivência era, sem dúvida, a luta usual e cotidiana da grande parte das mulheres chefes de domicilio. Era preciso sobreviver, sob condições muitas vezes adversas.

${ }_{14}$ Levamos em consideração, para efeitos de análise, somente as ocupaçōes representadas por mais de dez mulheres. 


\section{AS MULHERES PRIVILEGIADAS}

Havia um grupo restrito de mulheres que, efetivamente, não deve ter enfrentado grandes problemas em manter sua familia e seu grupo doméstico. Eram todas aquelas que eram denominadas "Donas", senhoras de cabedais nāo despreziveis.

Conforme já visto, esta categoria de mulheres dispunha sempre de plantéis mais ou menos amplos, mais do que suficientes para se sustentarem com certa folga. Algumas eram senhoras de engenho, proprietárias de fazendas de gado, lavradoras, ou mesmo viviam dos ganhos de seus escravos. Estas atividades econômicas, de grande porte, eram legadas pelos maridos, que confiavam às mãos dàs viúvas a direção dos negócios, mesmo quando possuíam filhos emancipados. Assim, em São Paulo colonial era plenamente aceitável um grande engenho de produção de açúcar ser possuído e dirigido por uma viúva, então denominada Senhora de Engenho.

Vivendo com um padrão de vida acima da média, algumas vezes ostentando grande fortuna, tais senhoras não exerciam, sob hipótese alguma, trabalhos manuais, restritos que eram a seus escravos e agregados. Também não enfrentavam grandes problemas no transmitir bens aos filhos, pois sempre havia um meio para dotá-los do mínimo necessário para se instalarem.

Regiam seus negócios com grande desenvoltura, tal como teriam feito seus maridos. Dona Francisca Clara Gomes, ao abrir processo para cobrança de dívida a João de Deus, afirma que «tem hua fazenda de criar no termo desta villa e como tal vende animais, crias da dita fazenda, assim a vista como fiado, no qual não há duvida" ${ }^{15}$. Após deixar clara sua posiçāo de grande proprietaria, relata, com minúcias, as diversas dividas que o réu Ihe fizera, no suceder de várias compras de animais, terminando por cobrar a divida há muito vencida. Tal como esta fazendeira, outra impetraram processos na justiça, em demanda de seus direitos e defesa de seus latifúndios.

\section{AS OUTRAS MULHERES: AS DESPOSSUIDAS}

Em contraposição à situação confortável das "Donas", havia o grande conjunto del mulheres que passava pelas mais sofriveis condições de vida.

${ }^{15}$ Autos Civeis de Sorocaba, 26.02.1795, N. ${ }^{\circ}$ Ordem 3.892. 
Solteiras, viúvas ou casadas, padeciam de crônica pobreza. Isto nāo as mantia, contudo, na defensiva, sofrendo as pressões de um mundo masculinizado, hostil ao «sexo frágil». Uma ampla documentação vem indicando que a mulher, mesmo aquela mais simples e despossuída de bens, lutava para garantir a sobrevivência e os seus parcos direitos. A Justiça, elesiástica ou leiga, era, via-de-regra, o espaço alternativo para que elas lutassem e defendessem seu lugar ao sol.

Essa mulher, branca, parda ou negra, exercia, segundo as listas nominativas, ocupações artesanais variadas, tais como costureira, rendeira, fiandeira e tecelã. A simplicidade descritiva das listas, contudo, não consegue mascarar a realidade, que não era assim tão demarcada em atividades ben definidas. Naquela sociedade rústica, o artesanato era apenas a ocupação principal, quase sempre secundada por outras ocupações ou, na forma mais comum, pela pequena lavoura de subsistência. As mulheres residentes nas vilas tendiam a exercer atividades várias, tais como venda de gêneros de quitanda, doces, e pequenos productos de seu grupo doméstico.

Se acompanharmos o mesmo fogo por anos a fio, através das listas, veremos como o recenseador variava nas denominações das ocupações daquele domicílio. A expressão "planta mantimentos para seu sustento" era, diversas vezes, substituída pelo termo "vadios", indocando os limites restritos entre o ínfimo produtor de alimentos para autoconsumo e a miséria. Bastava um ano de má colheita, e uma familia tornava-se "vadia", saindo, provavelmente, em busca de alimentos pela mendicância. Em 1798, Ana Maria, viúva e parda, "planta milho e feijão que mal the chega para passarm ${ }^{16}$.

Esta miséria quase absoluta, em que a mulher tem quase somente milho e feijão para sustentar aos seus, podia tambén ser comum entre as casadas, cujo marido estava ausente. $A$ ausência do marido não era fato novo na sociedade paulista. Desde princípios da colonização, o homem tendia a deixar sua família só quando partia em busca de riquezas minerais e do índio. Assim, o espaço doméstico vivia quase sempre em função da ausência de seu elemento masculino, exercendo a mulher o papel de mantenedora das necessidades cotidianas.

Principalmente em Sorocaba, mas também em Itu, os homens que se dedicavam ao tropeirismo costumavam deixar sós as esposas por largo espaço de tempo. Em 1801, temos a notícia de que Francisco Cubas estava "auzente para o Sul a 14 anos» deixando só sua esposa, Gertrudes Maria

${ }^{16}$ Lista nominativa de Sorocaba, 1789, 2. ${ }^{\mathrm{a}}$ Cia., fogo 26. 
Nogueira ${ }^{17}$. Caso idêntico ocorria com Joana Maria, cujo marido, Joaquim Caetano, negro, estava "auzente para Cuyaba a 9 anos" ${ }^{18}$, e com Caetana Maria, cujo marido, Manuel Roiz da Mota, estava também «auzente para o Sul a 8 anos» ${ }^{19}$.

O marido auzente poderia deixar auxilio para a subsistência de sua esposa. Josefa de Jesus declara que «vive da Assistencia q. Ihe deixou o marido" "20. Todavia, é óbvio que semelhante "asistência" jamais poderia ser suficiente para manter a esposa, e provável familia, por oito, nove ou quatorze anos seguidos, como ocorria nos exemplos acima citados.

Provavelmente, tais maridos eram tropeiros ou negociantes, mas suas mulheres surgem recenseadas, no mais das vezes, como fiandeiras, uma ocupação que, com certeza, não provinha os mesmo meios de susbsistência que aquela dos maridos.

A ausência do marido, e de seu peso econômico, levava muitas mulheres a difíceis situaçōes. Em 1793, Leonor Maria de Queirós solicita permissão ao Juiz para defender legalmente os bens do seu matrimônio de uma penhora, visto que "de prezente seacha seu marido José Pedrozo auzente..." ${ }^{21}$. Dois anos antes, Isabel Antunes Vieira, após declarar que "seacha com seu marido auzente fora da capitania», resolve solicitar ao Juiz que "lhe conceda licensa para poder requerer em juizo" contra uma invasão de suas terras ${ }^{22}$.

Mas, na verdade, a mulher solitária mostrava-se muito mais atuante do que isto. Invadia terras, negociava, metia-se em enrascadas, enfim, era senhora de seu destino, e buscava salvaguardá-lo, como qualquer homen o faria. Em 1795, Francisco Gonçalves e sua mulher acusam Josefa Moreira, viúva, de lhes invadir as terras, pois «por ser de má consciência, tendo pleno conhecimento de que aquellas terras são de legítimo domínio dos Autores e seus antepassados, dispoticamente tem plantado nellas e continua a plantar (...) para mais de alqueire e meio de milho de planta, introduzindo tambem na mesma terra dos Autores, gado, cavallos, e pondo-lhes fogos, com cujo empreendimento thes tem cauzado consideravel prejuizo" ${ }^{23}$. Como este processo, há inúmeros outros

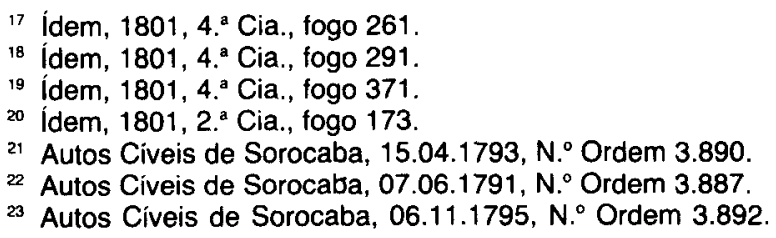


onde mulheres são acusadas de invadir terras, onde homens eram proprietários.

Mesmo em casos inversos, quando lavradores invadiam as terras de alguma mulher, esta não hesitava em levas à justiça seu protesto. Domingas de Oliveira, viúva, defende-se no ano de 1778, contra a invasão perpetrada por João da Silva Franco, alegando ser "senhora possuidora (...) de hum citio e terras lavradias na paragem cita Campo Largo cujas terras esta possuindo por sy e seos antepassados com poce passifica, mança, sem contradição, alguma, ha dez, vinte, trinta, coarenta e mais annos, e só João da Silva Franco esta perturbando e inquietando a suplicante (...), rossando e derrubando os matos das ditas terras, fazendo notoriamente esbulho (...), tirando a suplicante de sua poçe...». Não satisfeita com a expulsāo, exige o pagamento de "perdas e danos, e custas sobradas, e mais penas de direito", mostrando-se resoluta na defesa de seus interesses ${ }^{24}$.

Apesar de quase sempre analfabetas ${ }^{25}$, demonstram, em suas petições, estarem cientes de seus direitos: "diz Anna Custodia desta villa que ahu mez mais ou menos the vendeo Manuel Ribeiro de villa de Thaubathé huma escrava de nome Thereza por preço e quantia de setenta mil e quatrocentos reis que lhe pagou em moeda corrente e na certeza que Ihe vomprava fazenda sãa; e como pello contrario a dita escrava padece (... de the rebentarem feridas pelo corpo, que the faz trincar a pele dos braços, e pernas por onde verte agua, isto commummente nas conjunçoins, sem que o seu dito vendedor lhe declarou este defeito, de que era sabedor, no contrato da compra, por isso, como a suplicante pertende usar do direito que the assiste para emcampar ou regeitar a dita escrava, e julgando-ce nula a compra ... ${ }^{26}$.

Ativas e desembaraçadas, movendo ações contra aqueles que eram objeto de conflito, as mulheres solitárias garantiam sua sobrevivência. Não obstante sua atuação, diante da Justiça, tinha seus limites. Não eram costumeiramente aceitas, com algumas excessões, como testumunhas nas incontáveis devassas promovidas, regularmente, pelos mais variados motivos ${ }^{27}$.

${ }^{24}$ Autos Cíveis de Sorocaba, 13.08.1778, N. ${ }^{\circ}$ Ordem 3.878.

${ }^{25} \mathrm{O}$ analfabetismo era corrente, e não somente entre as mulheres. Em Itu, no ano de 1801, havia 53 domicilios chefiados por mulheres na $1 .^{a}$ Companhia, e somente três delas era alfabetizadas, sendo todas brancas e possuidoras de escravos.

${ }^{26}$ Autos Cíveis de Sorocaba, 19.09.1794, N. ${ }^{\circ}$ Ordem 3.891.

${ }^{27}$ Vide, por exemplo, nos Autos Civeis de Sorocaba, as devassas datadas de: 03.02.1796 ( $N .^{\circ}$ Ordem 3.894), sobre vistoria em cadáver; 08.07 .1795 ( $N .^{\circ}$ Ordem 3.892), 
Nas raras ocasiões em que testemunhavam, seu depoimento era constestado, através da insinuação de que o homem as manipulavam: «a testemunha $4 .^{a}$ Maria Vitoria foi peitada com promessa de a levar morar consigo, e fazer the muitos beneficios pello embargado. (...) que levada das promessas e caricias se rezolveu ajurar o que nāo sabia, tanto assim que o mesmo embargado a insinuou o que ella testemunha havia depor, como a mesma confessa..." ${ }^{28}$.

\section{A PROSTITUIÇÃO}

Há uma ocupação que, quase sempre, não é citada nos recenseamentos: a prostituição. Presentes em toda e qualquer vila, é "disfarçada" sob a classificação em outra atividade, que provavelmente se praticava no dia-a-dia: costureiras, fiandeiras, lavandeiras, etc. Mas, pelo menos uma vez, em Sorocaba, o recenseador deixou escapar a descrição de um fogo exclusivo de prostitutas:

“E seguem-se as meretrizes:

Ana Maria da Silva, parda, 22, solteira

Maria do Rozario, parda, 20, solteira

Ana Garcia, parda, 25, solteira

Ana Maria de Jesus, 25, solteira

Quiteria da Silva, 20, casada Jose, filho, 16, solteiro

Rosa Miz, 40, solteira

Joana Cubas, 30 , solteira Jose, filho, 12 , solteiro

Joana Pereira, 50 , viúva

Ana, criada, 10, solteira

Teresa Maria da Conceiçāo, 22, casada

Francisca Pinta, parda, 22, solteira

Ana Domingues, 16, solteira Jose, filho, 2

Rita Maria Carijó, 30, casada

Ana, filha, 4, solteira

Francisca Maria do Prado, 20, solteira

Maria Pereira de Jesus, 40, viúva

La..., filha, 16, solteira

sobre comércio ilegal de diamantes; 25.08 .1785 ( $\mathrm{N}^{\circ}$ Ordem 3.882 ), sobre agressão a um lavrador; 23.03.1766 ( $\mathrm{N} .{ }^{\circ}$ Ordem 3.872), sobre suborno em eleição.

${ }^{28}$ Autos Civeis de Sorocaba, 27.05.1805, N. ${ }^{\circ}$ Ordem 3.898. 
Josefa de Oliveira, 50, solteira

Tereza Maria da Luz, 20, solteira

Ignacia, forra, 10

Custodia Maria, 42, solteira

Maria Pereira, 29, solteira

Rita, filha, 14 , solteira

Micaela, mulata, forra, 20

Francisca do Rosario, 25, solteira

Ifigenia Maria, forra, 20" ${ }^{29}$.

A descrição deste domicílio legou-nos um raro testemunho de um censo a mostrar a diversidade da composição feminina do mundo da prostituição. Pardas, negras, forras e, por que não, brancas, todas se uniam na mesma atividade. A maioria era soiteira e jovem, mas havia as viúvas e casadas que, por falta de condiçōes de sobrevivência, recorriam à prostituição.

Estas mulheres se faziam muito presentes nos autos cíveis, envolvidas nos mais variados conflitos, de onde transparecia os preconceitos da sociedade contra sua atividade. Ao se envolverem com homens da vila, acabavam por sofrer vinganças de suas esposas ou de rivais políticos.

Em 1766, ao se abrir uma devassa para investigar as ameaças de agressão feitas a uma prostituta, trinta testemunhas são convocadas para depor. A primeira impressão que se tem, ao ler os depoimentos, era de que os homens buscavam disfarçar conhecerem as vitimas. Tendem a nem mesmo dar a entender que conheciam as atividades da vitima, $\mathrm{Te}$ resa Maria da Conceição ${ }^{30}$ : tratam-na como una mulher qualquer da vila. Alguns, contudo, deixam escapar detalhes sugestivos. Um «ouviu dizer de varias pessoas que se tinha dado hum tiro de noite na porta de Thereza por alcunha "a singela"..." ${ }^{31}$. Outro, diz que "... se deram huns tiros de noite na porta de humas mulheres da rua da palha..." ${ }^{32}$. Um velho lavrador afirma que o tiro fora "na porta de huma mulher mundana..." ${ }^{33}$. Por fim, a última testemunha parece resumir a questão: “sabe por ser publico e notório nesta villa que se tinhão dado huns tiros na porta de huma mulher donna per alcunha a singella.... ${ }^{34}$.

\footnotetext{
${ }^{29}$ Sorocaba. Lista nominativa de $1771,1 .^{\mathrm{a}}$ Cia., fogo sem número.

30 Que também está citada na lista das meretrizes, já transcrita.

${ }^{31}$ Depoimento de João Dias Vieira. 09.09.1766, N. ${ }^{\circ}$ Ordem 3.872.

${ }^{32}$ Depoimento de Antonio Valente Vidigal. Idem.

${ }^{33}$ Depoimento de Ventura de Araujo Ferreira. Idem.

${ }^{34}$ Depoimento de Antonio Braga Morais. Idem.
} 
Este longo processo, findo em 24.12.1776, nada consegue provar. Todavia, antes mesmo dessa ação judicial se encerrar, outra devassa já havia sido instaurada, de forma independente, tratando justamente da concretização das ameaças feitas anteriormente à mesma Teresa, que desta feita foi efeitivamente espancada. Iniciada aos 10.111.766, essa nova ação determina a oitiva de trinta testemunhas, algumas já ouvidas anteriomente.

Como agora a agressão se efetivara, o problema era bem mais sério, e as testemunhas parecem conhecer maiores detalhes do conflito. Todas acusam, quase unanimamente, "a gente do Coroinha Manuel de Morais", personagem conhecida da vila. Mulheres de posição social elevada, talvez por vingança contra meretrizes que mantinham encontros com seus maridos, são, com nitidez, as agressoras. O evoluir dos depoimentos apontam, contudo, para uma realidade «desagradável»: as agressoras e seus cúmplices eram membros do grupo familiar mais poderoso da vila, chefiado pelo Capitão Mor Cláudio de Madureira Calheiros. $\mathrm{N}$-ão era possivel a penalizaçāo dos culpados, apesar da grande transparência do evento. Conclue-se: "Não obriga esta devassa a pessoa algua, vista a variedade com que depoem as testemunhas sem conluirem nem darem cabal razão do seu dito" ${ }^{35}$.

A atividade da prostituição envolve mulheres, com laços afetivos sólidos, a vários homens, criando situaçōes constrangedoras. Em 1787, Barbara Maria, «mulher prostituta», foge da cadeia graças à ajuda de João Ferreira ${ }^{36}$.

\section{CONCLUSÃO}

A mulher solitária era uma categoria frequente em nossa sociedade colonial. As opções para o matrimônio, para as solteiras, eram dificeis, seja pela ausência de cônjuges, seja pela absoluta falta de recursos econômicos. Para as viúvas, o recasamento seria uma solução, mas era pouco usual. Para as casadas, enfim, restava esperar pela volta dos maridos, muitas vezes nunca ocorrida.

${ }^{35}$ Autos Civeis de Sorocaba. Devassa, Sentença dada aos 22.12.1766. N. ${ }^{\circ}$ Ordem 3.872 .

${ }^{36}$ Autos Civeis de Sorocaba, 12.12.1787. N. ${ }^{\circ}$ Ordem 3.883. 
Sem um cônjuge, precisavam se arranjar sózinhas. Algumas, ricas, continuavam sua rotina diária. A maioria, sem posses, buscava caminhos para o sustento. Este caminhos eram múltiplos. Havia aquelas que permaneciam em suas roças, buscando a sobrevivência pela lavoura. Outras, em maior número, se estabeleciam no núcleo urbano, onde as possibilidades de trabalho eram mais abundantes. Outras, enfim, não obtinham sucesso em suas tentativas, e buscavam a prostituição ou a mendicância.

Fosse quat fosse a atividade desenvolvida, essas mulheres, não importando a cor ou o estado matrimonial, procuravam defender, de um modo ou de outro, seus interesses. Lutavam na justiça, onde seus direitos podiam ser reconhecidos. No campo, enfrentavam seus vizinhos, homens na maioria, com desembaraço e mesmo com agressividade, ocupando terras, invadindo campos com seus animais e instalando suas roças.

Temos, pois, uma mulher economicamente muito ativa, fartamente presente em ações civeis de cobrança de dividas, tanto como autora quanto ré. Embora muitos espaços thes fossem vedados -os cargos públicos, a magistratura- nada nos permite visualizá-las como recolhidas em suas casas, deixando o mundo da rua reservado somente aos homens. 